\title{
Oxidation of Stainless Steel Powder
}

\author{
Jinane Tarabay $•$ Véronique Peres $\cdot$ Michèle Pijolat
}

Received: 10 July 2012/Published online: 21 February 2013

(C) The Author(s) 2013. This article is published with open access at Springerlink.com

\begin{abstract}
To understand the corrosion behavior of a model 304L(p)$\mathrm{ZrO}_{2}$ (s) composite, a 304L stainless steel powder was studied under oxygen at high temperature. Oxidation tests were performed with thermogravimetry. The so-called jumps method, which involves a sudden change of the temperature, was also applied to propose a kinetic model. Two periods with different rate-determining steps could be distinguished for short $(<12 \mathrm{~h})$ and long time experiments $(12-20 \mathrm{~h})$. SEM observations of oxidized particles revealed an oxide layer structure similar to that of alloy plates of same composition: during the first ten hours period, the external scale surrounding stainless steel particles was found to be chromium oxide; for the second oxidation period, the outer oxide layer was enriched in iron. Considering the relatively short-term oxidation period, a kinetic model based on an outward growth of chromia from oxidation of $\mathrm{Cr}$ in solution in the spherical alloy particles was successfully compared to the experimental mass gain curve. The $\mathrm{k}_{\mathrm{p}}$ value deduced from this modeling was found to be in agreement with the literature data. The diffusion of interstitial chromium ions is the rate-determining step in agreement with the absence of influence of the oxygen partial pressure.
\end{abstract}

Keywords Powder $\cdot$ Stainless steel $\cdot$ Oxidation

\footnotetext{
J. Tarabay $\cdot$ V. Peres $(\bowtie) \cdot$ M. Pijolat

Ecole Nationale Supérieure des Mines, SPIN-EMSE, CNRS:UMR 5307 LGF,

42023 Saint-Étienne, France

e-mail: peres@emse.fr

J. Tarabay

e-mail: tarabay@emse.fr

M. Pijolat

e-mail: mpijolat@emse.fr
} 


\section{Introduction}

Ceramic matrix composites dispersed with metal particles, called M(p)-CMC(s) [1], are one of the promising materials for high performance applications under some severe environment such as high temperature. This new material design offers the possibility to combine heat resistance, corrosion resistance and wear resistance due to the ceramic phase, with mechanical strength and electric conductivity provided by the metal phase.

The oxidation at $800{ }^{\circ} \mathrm{C}$ of a model M(p)-CMC(s) composite based on zirconia and $304 \mathrm{~L}$ stainless steel materials seem to be very complicated, a rapid mass gain occurs as soon as oxygen is introduced. After this short period the mass gain curves take a parabolic shape. To understand this unusual behavior, we decide to study the oxidation of the stainless steel powder alone.

This work based on thermogravimetry (TGA) experiments under $20 \% \mathrm{O}_{2}-80 \%$ $\mathrm{He}$ at $1 \mathrm{~atm}$ presents the oxidation behavior at $800{ }^{\circ} \mathrm{C}$ of the stainless steel powder.

\section{Experimental Procedures}

The experiments were carried out on water-atomized 304L austenitic stainless steel powder provided by Hoganas Belgium. The chemical composition of the alloy established by the supplier is summarized in Table 1. Its specific surface area measured with the BET method is $0.06 \mathrm{~m}^{2} \mathrm{~g}^{-1}$. Various particle size classes, from 0 to $50 \mu \mathrm{m}$ fraction up to a fraction $>100 \mu \mathrm{m}$, have been obtained after sieving the steel powder.

The particle size distribution in volume, established by laser granulometry (Malvern instruments, Mastersizer 2000) reveals one main mode particle diameter at $80 \mu \mathrm{m}$ (Fig. 1).

\section{Test Facility and Conditions}

Oxidation experiments were performed in a symmetric thermogravimetric analyzer (SETARAM TGA16 with a thermocouple PtRh $6 \% / \mathrm{PtRh} 30 \%$ ) at $800{ }^{\circ} \mathrm{C}$ for $6 \mathrm{~h}$ in a flowing mixture of helium and oxygen. The composition in oxygen was varied in the range 10-40 vol\%. The tests were carried out at atmospheric pressure with a total gas flow rate of $2 \mathrm{~L} \mathrm{~h}^{-1}$ in each furnace. Samples consist of small beds $(10 \mathrm{mg})$ of stainless steel powder placed in an alumina crucible.

The TGA experiments consisted of three main consecutive steps: heating to $800{ }^{\circ} \mathrm{C}$ with a rate of $30{ }^{\circ} \mathrm{C} \mathrm{min}{ }^{-1}$ under helium, isothermal exposure under oxygen helium mixture at $800{ }^{\circ} \mathrm{C}$ during various periods up to $20 \mathrm{~h}$, cooling to room

Table 1 Chemical composition of 304L stainless steel

\begin{tabular}{llllr}
\hline Weight $(\%)$ & $\mathrm{Fe}$ & $\mathrm{Cr}$ & $\mathrm{Ni}$ & $\mathrm{Si}$ \\
\hline & Base & 18.1 & 11.3 & 0.85 \\
\hline
\end{tabular}


Fig. 1 Grain size distribution of 304L stainless steel powder

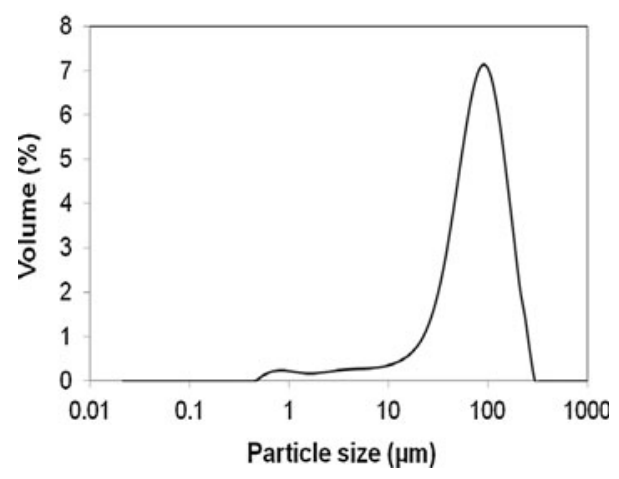

temperature with a rate of $30{ }^{\circ} \mathrm{C} \min ^{-1}$ under oxygen helium mixture. The oxygen is introduced after $7 \mathrm{~min}$ at $800{ }^{\circ} \mathrm{C}$. The oxygen impurity in helium was analyzed at the outlet of the furnace by an oxygen probe (Systech Instruments Série 900) with an accuracy of about $1 \mathrm{ppm}$ at $20{ }^{\circ} \mathrm{C}$.

\section{Results}

\section{TGA Results}

A lack of reproducibility of the oxidation curves of 304L stainless steel powder is observed which is mainly due to a difference in particle size. The mass gain curves vs time for the as received 304L powder and for the various particles size classes are shown in Fig. 2. It can be seen that a good reproducibility was obtained with each

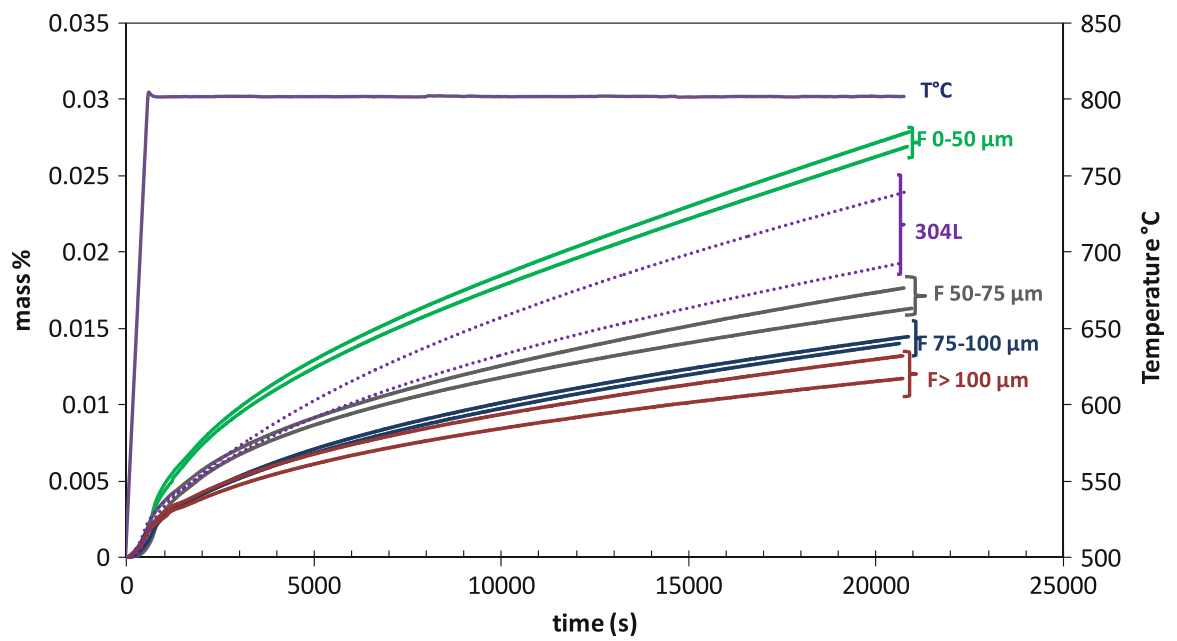

Fig. 2 Mass gain (\%) versus time of as received and sieved 304L stainless steel powders oxidized at $800{ }^{\circ} \mathrm{C}\left(20 \%\right.$ in volume of $\mathrm{O}_{2}$ in helium) 


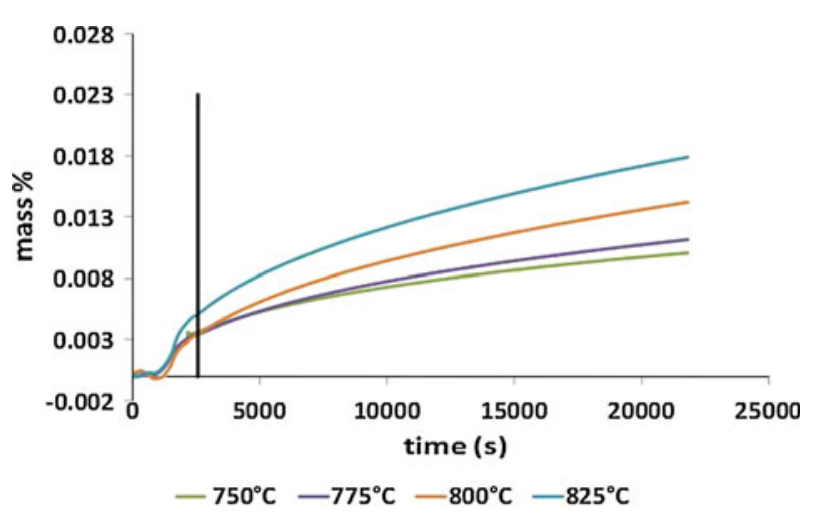

Fig. 3 Mass gain (\%) versus time of $75-100 \mu \mathrm{m}$ class of 304L stainless steel powder oxidized under $20 \%$ in volume of $\mathrm{O}_{2}$ at $750,775,800$ and $825^{\circ} \mathrm{C}$

particle size class of sieved powders, whereas the curves obtained with the as received 304L powder were not so well reproducible.

The powder with the finest particles class $(0-50 \mu \mathrm{m})$ shows greatest mass gain than the as received powder, while the largest one $(>100 \mu \mathrm{m})$ shows least mass gain. The curves of the intermediate particle-size classes $(50-75 \mu \mathrm{m}$ and 75-100 $\mu \mathrm{m}$ ) fall between those extreme curves. The reproducibility of the oxidation curves of the particle-size class $(75-100 \mu \mathrm{m})$ is the best one, so this 304L stainless steel powder fraction has been used for the kinetic study.

The first part of the mass gain curves corresponds to the heating under helium up to the introduction of oxygen at the beginning of the plateau at $800{ }^{\circ} \mathrm{C}$. The small mass change during the first period is due to oxygen traces in helium (50 ppm).

Figure 3 illustrates the mass gain curves versus time (under isobaric and isothermal conditions) for samples oxidized at different temperatures under $20 \%$ in volume of $\mathrm{O}_{2}$. As expected, the mass gain increases with the temperature increase.

Figure 4 illustrates the mass gain curves versus time (under isobaric and isothermal conditions) for samples oxidized at $800{ }^{\circ} \mathrm{C}$ under 10,20 and $40 \%$ in volume of $\mathrm{O}_{2}$. The curves are superimposed; it means that there is no influence of oxygen partial pressure on the kinetic behavior of 304L stainless steel powder.

\section{Characterization of 304L Stainless Steel Powder}

Figure 5a and b show individual metal alloyed particles of stainless steel powder. A native $\mathrm{Cr}_{2} \mathrm{O}_{3}$ layer around the particles can be observed. During water-atomization the powder is oxidized [2,3].

Figures $6 \mathrm{a}$ and $\mathrm{b}$ show SEM observations of the powder oxidized during respectively 6 and $20 \mathrm{~h}$. The particles exhibit an external $\mathrm{Cr}_{2} \mathrm{O}_{3}$ layer growth surrounding the metallic particles. The scale begins to loose adherence after $20 \mathrm{~h}$ of oxidation. EDX analysis (Fig. 7) shows that the outermost layer is composed of an iron rich mixed oxide phase. 


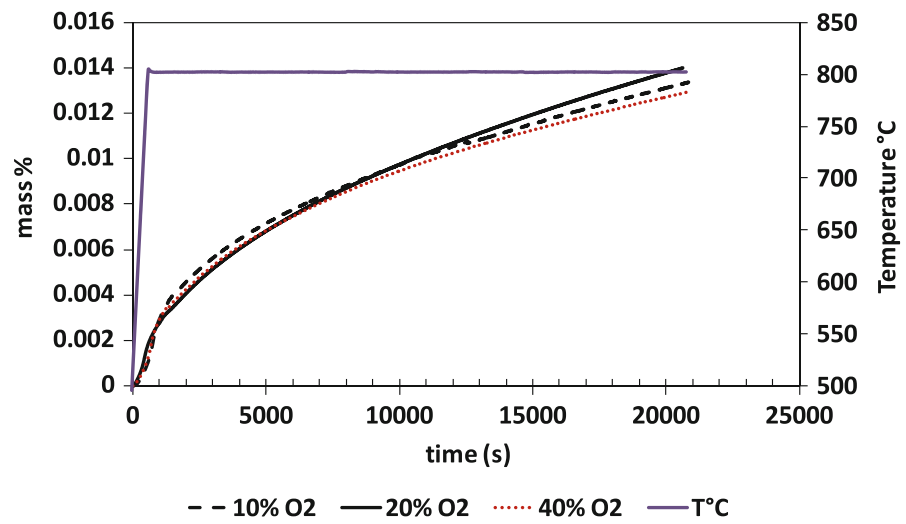

Fig. 4 Mass gain (\%) versus time of 75-100 $\mu \mathrm{m}$ class of $304 \mathrm{~L}$ stainless steel powder oxidized at $800{ }^{\circ} \mathrm{C}$ under $10 \%$ (black dotted line), $20 \%$ (black continuous line), $40 \%$ (red fine dotted line) in volume of $\mathrm{O}_{2}$ (Color figure online)

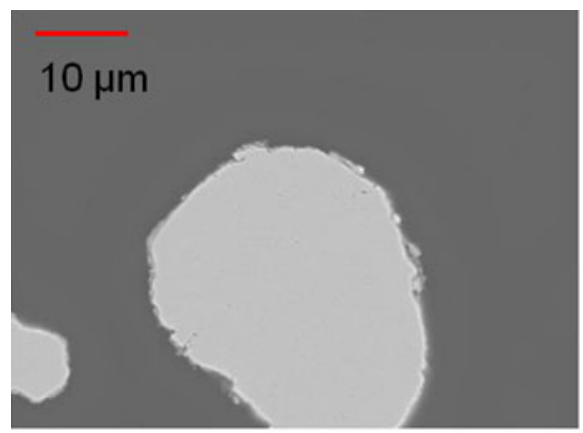

(a)

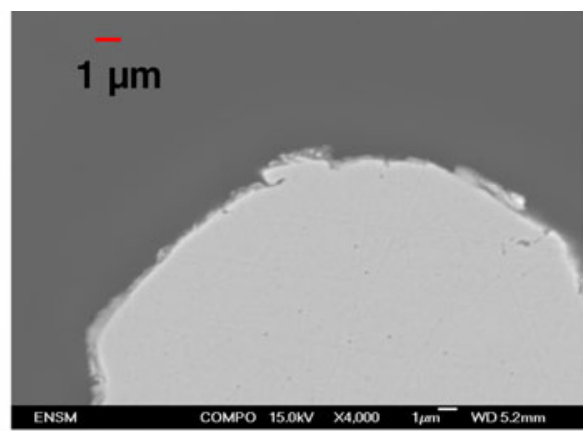

(b)

Fig. 5 SEM observations of starting 304L stainless steel powder

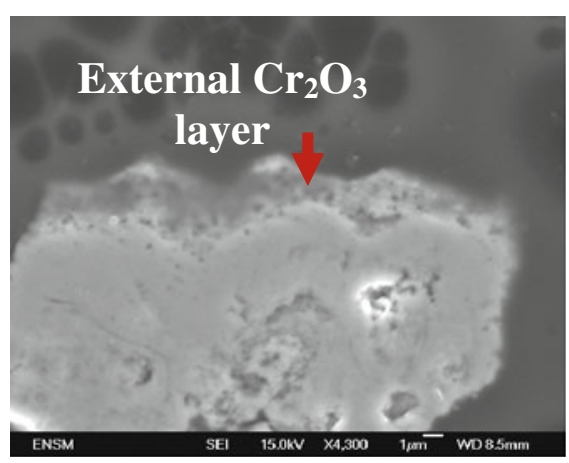

(a)

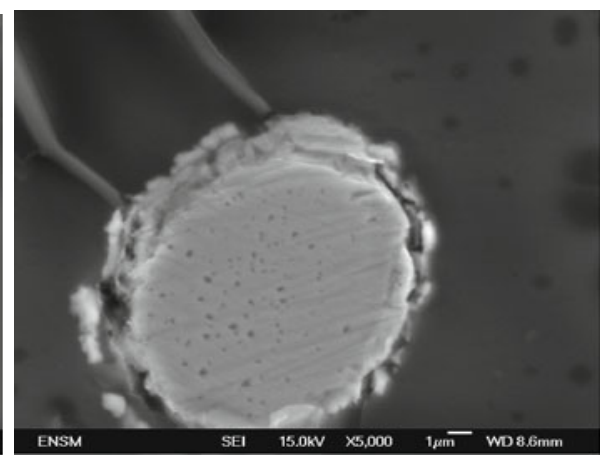

(b)

Fig. 6 SEM observations of 304L stainless steel powder oxidized at $800{ }^{\circ} \mathrm{C}$ after $6 \mathrm{~h}$ (a) and $20 \mathrm{~h}(\mathbf{b})$ 


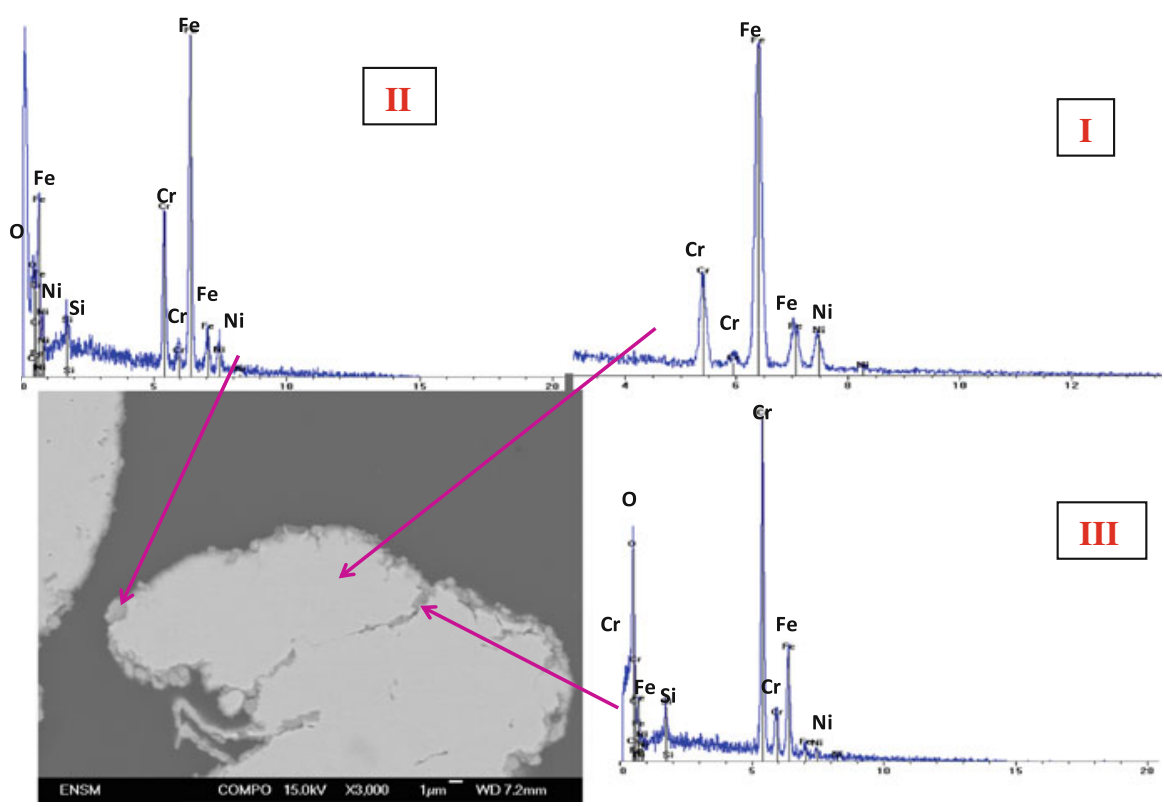

Fig. 7 EDX analysis of 304L stainless steel powder oxidized at $800{ }^{\circ} \mathrm{C}$ after $20 \mathrm{~h}$

\section{Discussion}

The oxidation of 304L stainless steel powder shows a parabolic like behavior with an external $\mathrm{Cr}_{2} \mathrm{O}_{3}$ layer growth. According to literature data concerning the oxidation of 304L foils [4-6], the oxide growth should be controlled by the diffusion of cations. Assuming that the $\mathrm{Cr}_{2} \mathrm{O}_{3}$ layer remains very thin compared to the particle radii, a parabolic law could account for the experimental mass gain curves. Due to the existence of an initial native oxide layer, the complete parabolic law (Eq. 1) has been applied to the experimental data, the mass gain is normalized by the surface area of the powder (Fig. 8) [7]. The fitted value of $\mathrm{k}_{\mathrm{p}}$ is equal to $2.5 \times 10^{-12} \mathrm{~g}^{2} \mathrm{~cm}^{-4} \mathrm{~s}^{-1}$ in agreement with the literature data for $\mathrm{Cr}_{2} \mathrm{O}_{3}$ growth (at $800^{\circ} \mathrm{C}: \mathrm{k}_{\mathrm{p}}=8 \times 10^{-12} \mathrm{~g}^{2} \mathrm{~cm}^{-4} \mathrm{~s}^{-1}$ ) [8].

$$
t=A+B \Delta m+\frac{1}{k_{P}} \Delta m^{2}
$$

However, a much more detailed kinetic analysis can be undertaken considering the kinetics of solid-gas reactions with powders. Solid gas reaction kinetic modeling is based on the assumption of the rate determining step which can be validated using the " $\phi S_{\mathrm{m}}$ " test based on the jumps method $[9,10]$. Such a method consists of a sudden jump in a thermodynamic variable (temperature or pressure) from an initial value to a final one and uses the ratios of the kinetic rates measured after/before this jump.

When the reaction is controlled by diffusion or by an interfacial step, the kinetic rate expressed as $\mathrm{d} \alpha / \mathrm{dt}$ (where $\alpha$ is the fractional conversion), is given by: 


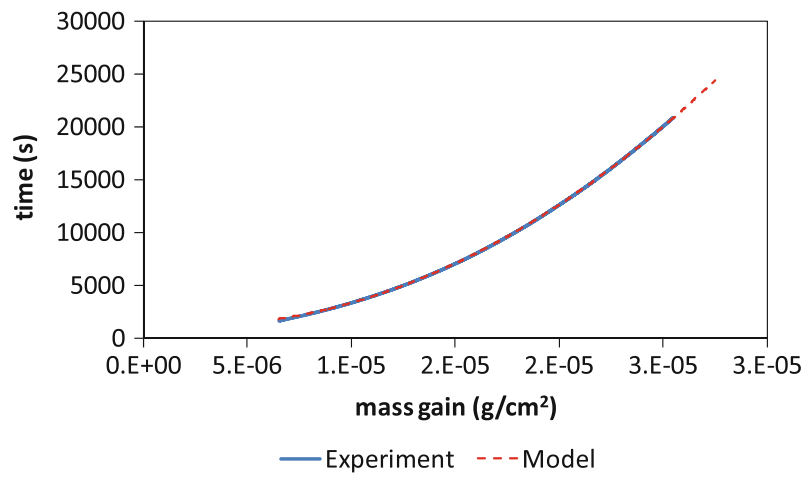

Fig. 8 Oxidation of $304 \mathrm{~L}$ stainless steel powder at $800{ }^{\circ} \mathrm{C}$ : experimental curve and complete parabolic law

$$
\frac{\mathrm{d} \alpha}{\mathrm{dt}}=\phi(\mathrm{T}, \mathrm{Pi}, \ldots) \cdot \mathrm{S}_{\mathrm{m}}(\mathrm{t})
$$

where $\phi(T, P i, \ldots)$ is the areic rate of growth $\left(\mathrm{mol} \mathrm{m} \mathrm{m}^{-2} \mathrm{~s}^{-1}\right)$, and $\mathrm{S}_{\mathrm{m}}(\mathrm{t})$ is the space function $\left(\mathrm{m}^{2} \mathrm{~mol}^{-1}\right)$ related to the extent of the reaction area where the ratedetermining step takes place, which depends on the time and on the history of the solid. The jumps method was applied in our tests by a sudden change of the temperature from $\mathrm{T}_{0}=780{ }^{\circ} \mathrm{C}$ to $\mathrm{T}_{1}=800{ }^{\circ} \mathrm{C}$ at various mass gains. Figure 9 illustrates the ratio of the kinetic rates $(\mathrm{R})$ after/before the jump versus mass gain. The " $\phi \mathrm{S}_{\mathrm{m}}$ " test is validated if the ratio of values does not depend of the mass gain at which the jumps are done. Figure 9 shows that we can consider two domains, in the first domain until $9 \mathrm{~h}$ the ratios take a constant value around $1.45 \pm 0.05$, in the second domain after $12 \mathrm{~h}$ of treatment the ratios are also constant, the value is higher around $2 \pm 0.01$. The " $\phi \mathrm{S}_{\mathrm{m}}$ " test is validated in both separate domains. In each of these areas the oxidation rate of $304 \mathrm{~L}$ powder $(75-100 \mu \mathrm{m})$ can be decomposed into a product functions according to Eq. (2). There is thus in both cases a step of the growth mechanism of the oxide which controls the speed of the reaction. However, after a certain oxidation time (from $12 \mathrm{~h}$ ), a different ratedetermining step and/or a different mechanism should be considered. Based on the literature and SEM/EDX observations of 304L powder oxidized after 6 and $20 \mathrm{~h}$, we can assume that, at first, it is the diffusion of $\mathrm{Cr}^{3+}$ ions which determines the rate of reaction. Then from a certain thickness of chromium oxide, it is the diffusion of $\mathrm{Fe}^{3+}$ which limits the rate, the outer oxide layer becoming rich in iron.

Assuming an Arrhenius behavior for the dependence of $\phi$ with temperature, the activation energy calculated from the first domain ratio is about $177 \mathrm{~kJ} \mathrm{~mol}^{-1}$ which is rather similar to that of $\mathrm{Cr} / \mathrm{Cr}_{2} \mathrm{O}_{3}$ reaction $\left(158 \mathrm{~kJ} \mathrm{~mol}^{-1}\right)$ [11]. For the second domain, the apparent activation energy is about $322 \mathrm{~kJ} \mathrm{~mol}^{-1}$. Consequently this higher apparent activation energy should correspond to the growth of the mixed oxide rich in iron. 


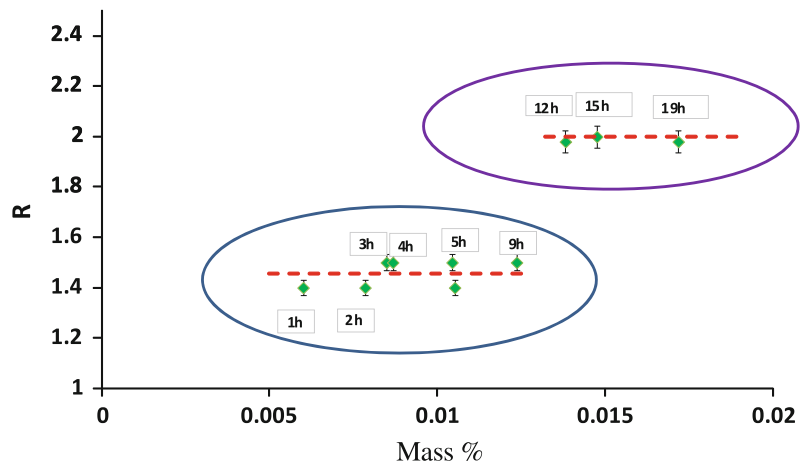

Fig. 9 Oxidation of 304L stainless steel powder: ratio R for jumps changes from 780 to $800{ }^{\circ} \mathrm{C}(20 \%$ $\left.\mathrm{O}_{2}\right)$

Fig. 10 Scheme illustrating the oxide layer (thickness equal to $\mathrm{r}_{\mathrm{e}}-\mathrm{r}_{0}$ ) around a spherical stainless steel powder particle with $\mathrm{r}_{0}$ initial radius

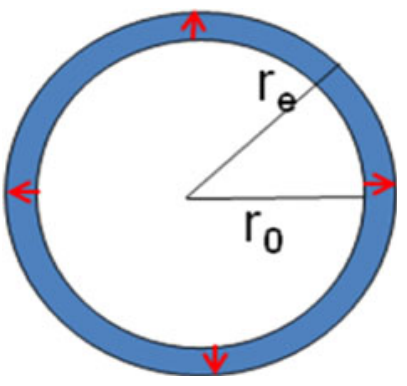

\section{Kinetic Model}

In the first domain (short oxidation time), the rate law can be obtained using the assumption that the rate-determining step corresponds to the external $\mathrm{Cr}_{2} \mathrm{O}_{3}$ oxide layer growth around the stainless steel powder particles, considered as spherical (Fig. 10). The oxidation is controlled by the diffusion of $\mathrm{Cr}$ cations through the oxide layer.

The rate law is given by:

$$
\frac{\mathrm{d} \alpha}{\mathrm{dt}}=\mathrm{J}_{\mathrm{Cr}} \cdot \frac{\mathrm{s}}{\mathrm{n}_{0}}
$$

where $\mathrm{s}$ is the initial surface of a stainless steel particle, $\mathrm{n}_{0}$ is the initial mole number of $\mathrm{Cr}$ in the $304 \mathrm{~L}$ stainless steel and $\mathrm{J}_{\mathrm{Cr}}$, the diffusion flow in $\mathrm{mol} \mathrm{m}^{-2} \mathrm{~s}^{-1}$, is given by:

$$
\mathrm{J}_{\mathrm{Cr}}=\mathrm{D}_{\mathrm{Cr}}|\Delta \mathrm{C}| \frac{\mathrm{r}_{\mathrm{e}}}{\mathrm{r}_{0}\left(\mathrm{r}_{\mathrm{e}}-\mathrm{r}_{0}\right)}
$$

where $\mathrm{D}_{\mathrm{Cr}}$ is the diffusion coefficient of $\mathrm{Cr}$ in $\mathrm{m}^{2} \mathrm{~s}^{-1}, \Delta \mathrm{C}$ is the difference in the $\mathrm{Cr}$ concentration at both sides of the diffusion layer. 
Knowing that the fractional conversion $\alpha$ represents the ratio between the experimental mass obtained from TGA and the theoretic mass necessary for total oxidation of chromium in the stainless steel (18 wt $\%), \alpha$ the fractional conversion can be written by:

$$
\alpha=\frac{\mathrm{n}_{\mathrm{Cr}_{2} \mathrm{O}_{3}}}{\frac{1}{2} \mathrm{n}_{0}}=\frac{2}{\mathrm{n}_{0} \cdot \mathrm{V}_{\mathrm{m}_{\mathrm{ox}}}} \cdot\left(\frac{4}{3} \cdot \pi \cdot \mathrm{r}_{\mathrm{e}}^{3}-\frac{4}{3} \cdot \pi \cdot \mathrm{r}_{0}^{3}\right)
$$

where $\mathrm{n}_{0}$ is the mole number of $\mathrm{Cr}$ in the sample of powder of mass $\mathrm{m}_{0}$

$$
\mathrm{n}_{0}=\frac{\mathrm{m}_{0} \cdot 0.18}{\mathrm{M}_{\mathrm{Cr}}}
$$

and $\mathrm{n}_{\mathrm{Cr}_{2} \mathrm{O}_{3}}$ is the mole number of $\mathrm{Cr}_{2} \mathrm{O}_{3}$ formed, $\mathrm{V}_{\text {mox }}$ is the molar volume of $\mathrm{Cr}_{2} \mathrm{O}_{3}$. From Eq. (5), $r_{e}$ can be expressed by:

$$
\mathrm{r}_{\mathrm{e}}=\mathrm{r}_{0}\left(1+\frac{3 \cdot \mathrm{n}_{0} \cdot \mathrm{V}_{\mathrm{m}_{\mathrm{ox}}} \cdot \alpha}{8 \cdot \pi \cdot \mathrm{r}_{0}^{3}}\right)^{1 / 3}
$$

with $r_{0}$ the mean radius equal to 43 microns considering the T-304L stainless steel powder $(75-100 \mu \mathrm{m})$ particles as spherical.Thus the rate law can be written as:

$$
\frac{\mathrm{d} \alpha}{\mathrm{dt}}=\phi \cdot \frac{4 \cdot \pi \cdot \mathrm{r}_{0}}{\mathrm{n}_{0}} \frac{\left(1+\frac{3 \cdot \mathrm{n}_{0} \cdot \mathrm{v}_{\mathrm{m}_{\mathrm{ox}}} \cdot \alpha}{8 \cdot \pi \cdot \mathrm{r}_{0}^{3}}\right)^{1 / 3}}{\left[\left(1+\frac{3 \cdot \mathrm{n}_{0} \cdot \mathrm{v}_{\mathrm{m}_{\mathrm{ox}}} \cdot \alpha}{8 \cdot \pi \cdot \mathrm{r}_{0}^{3}}\right)^{1 / 3}-1\right]}
$$

In this expression, $\alpha$ the fractional conversion is the ratio of the experimental mass change $\Delta \mathrm{m}$ relative to the mass variation theoretically needed to oxidize the chromium in the alloy. The value of $\alpha$ can be calculated from the experimental mass change $\Delta \mathrm{m}$ versus time according to Eq. (9):

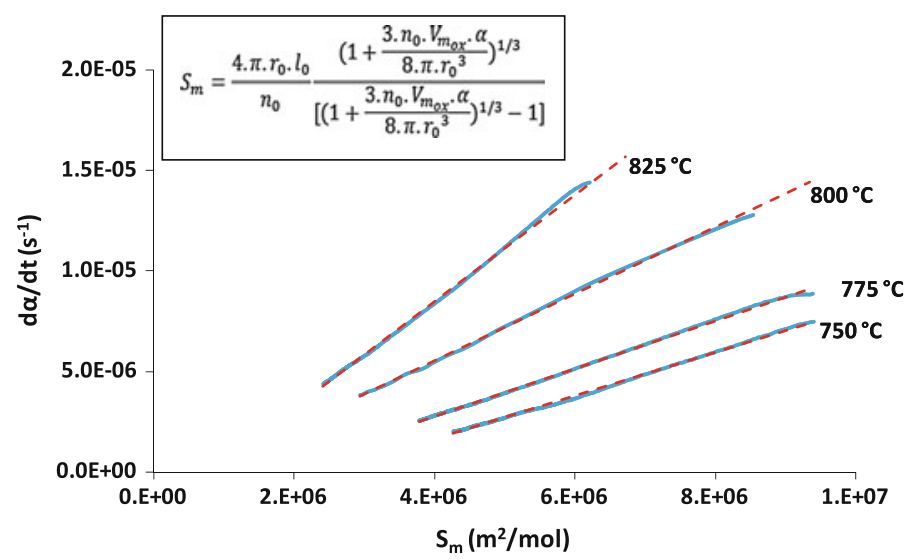

Fig. 11 Oxidation of 304L stainless steel powder : experimental data (blue continuous lines) and theoretical rate laws (red dotted lines) (Color figure online) 


$$
\alpha=\frac{\Delta \mathrm{m}}{\Delta \mathrm{m}_{\mathrm{th}}}=\frac{\Delta \mathrm{m}}{\frac{3}{4} \cdot \mathrm{M}_{\mathrm{O}_{2}} \cdot \mathrm{n}_{0}}
$$

with $\mathrm{M}_{\mathrm{O}_{2}}$ the oxygen molecular weight.

Figure 11 represents the fits between the kinetic data $(\mathrm{d} \alpha / \mathrm{dt})$ and the theoretical rate law considering $\mathrm{S}_{\mathrm{m}}$ function [cf. Eqs. (2) and (8)].

Only the kinetic data corresponding to the first oxidation domain between 0 and $9 \mathrm{~h}$ give a straight line whose the slope of $\mathrm{d} \alpha / \mathrm{dt}=\phi \mathrm{S}_{\mathrm{m}}$ give the value of $\phi$ at each temperature. The model is thus found in good agreement with experimental data.

Table 2 shows the values of $\phi$ for temperatures between 750 and $825{ }^{\circ} \mathrm{C}$.

Based on these data, and plotting $\ln \phi$ as a function of 1/T (Fig. 12), a straight line is obtained with an acceptable coefficient of correlation showing that $\phi$ depends on the temperature according to the Arrhenius law. The apparent activation energy obtained is equal to $139 \mathrm{~kJ} / \mathrm{mol}$. This value is significantly lower than that of the value previously calculated from the ratio of the kinetic rates in the short time period (cf. Figure 9), but nevertheless, the two methods of calculation give values of apparent activation energy close to $158 \mathrm{~kJ} / \mathrm{mol}$, which correspond to the system $\mathrm{Cr} / \mathrm{Cr}_{2} \mathrm{O}_{3}$.

Relation Between $\phi$ and $\mathrm{k}_{\mathrm{p}}$

$\phi$ and $\mathrm{k}_{\mathrm{p}}$ are temperature dependent and they represent quantities obtained for the same diffusion controlling step but in different geometries (spheres and plates respectively). In a planar geometry, the fractional conversion $\alpha$ is given by:

Table $2 \phi$ values at different temperatures

\begin{tabular}{ll}
\hline Temperature $\left({ }^{\circ} \mathrm{C}\right)$ & $\phi\left(\mathrm{mol} \mathrm{m}^{2} \mathrm{~s}^{-1}\right) \times 10^{-12}$ \\
\hline 750 & 0.76 \\
775 & 0.85 \\
800 & 1.59 \\
825 & 2.13 \\
\hline
\end{tabular}

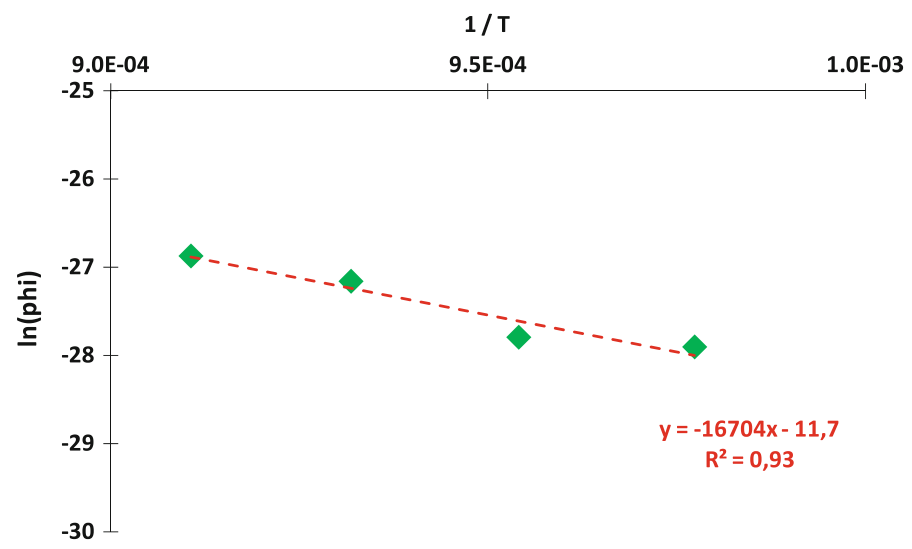

Fig. 12 Variation of $\ln \phi$ versus $1 / \mathrm{T}\left(\mathrm{K}^{-1}\right)$ 


$$
\alpha=\frac{4}{3} \cdot \frac{1}{n_{0} M_{O_{2}}} \cdot \Delta m
$$

The kinetic rate is given by:

$$
\frac{d \alpha}{d t}=\phi \cdot S_{m}=\phi \cdot \frac{l_{0}}{x} \cdot \frac{\varepsilon}{n_{0}}
$$

where $l_{0}$ is a length equal to unity $(1 \mathrm{~m}), \mathrm{X}$ is the thickness of the oxide layer expressed by Eq. (12):

$$
\mathrm{X}=\frac{2 \mathrm{Vm}_{\mathrm{ox}}}{3 \mathrm{M}_{\mathrm{O}_{2}}} \cdot \frac{\Delta \mathrm{m}}{\mathrm{s}}
$$

The relationship between $\mathrm{k}_{\mathrm{p}}$ and $\phi$ is established from the combination of Eq. (11) and of the derivative of Eq. (1),

$$
\mathrm{k}_{\mathrm{p}}=\frac{1_{\mathrm{o}} 3^{2} \mathrm{M}_{\mathrm{O}_{2}}^{2}}{4 \mathrm{Vm}_{\mathrm{ox}}} \phi
$$

At $800{ }^{\circ} \mathrm{C}$, based on the value of $\phi, \mathrm{k}_{\mathrm{p}}$ is equal to $2 \times 10^{-12} \mathrm{~g}^{2} \mathrm{~cm}^{-4} \mathrm{~s}^{-1}$. This value is in good agreement with the value found using the complete parabolic law: $\mathrm{k}_{\mathrm{p}}=2.5 \times 10^{-12} \mathrm{~g}^{2} \mathrm{~cm}^{-4} \mathrm{~s}^{-1}$ and with literature data confirming the similar behavior between 304L plates and powder.

\section{Conclusions}

This study has put in evidence a conventional oxidation of the 304L stainless steel powder with a parabolic like behavior. The fitted $\mathrm{k}_{\mathrm{p}}$ value calculated with a complete parabolic law is similar to literature data. From the jumps method, two distinct rate-determining steps were observed for short $(<12 \mathrm{~h})$ and long $(>12 \mathrm{~h})$ oxidation times at $780-800{ }^{\circ} \mathrm{C}$. Based on bibliographic data and SEM analysis, the first period was attributed to the outward oxidation of $\mathrm{Cr}$ forming an external $\mathrm{Cr}_{2} \mathrm{O}_{3}$ layer, while the second period was attributed to the growth of an iron-rich mixed oxide at the outermost oxide scale. A kinetic model devoted to the oxidation in $\mathrm{Cr}$ in solution in spherical particles of 304L was established and allowed to fit the short oxidation kinetic data. The $\mathrm{k}_{\mathrm{p}}$ value deduced from this model was in agreement with the literature data obtained for plates, indicating a similar behavior of the 304L stainless steel powder.

This study will help us to understand the unusual oxidation behavior of a model composite elaborated with 304L stainless steel particles inserted in an yttrium stabilized zirconia matrix which seems to play a basic role in the early stage of the composite oxidation process.

Open Access This article is distributed under the terms of the Creative Commons Attribution License which permits any use, distribution, and reproduction in any medium, provided the original author(s) and the source are credited. 


\section{References}

1. M. Nanko, Science and Technology of Advanced Materials 6, 129 (2005).

2. A. Nylund, T. Tunberg, H. Bertilsson, E. Carlstrom, and I. Olefjord, The International Journal of Powder Metallurgy 31, 365 (1995).

3. M. Norell, A. Nyborg, T. Tunberg, and I. Olefjord, Surface and Interface Analysis 19, 71 (1992).

4. V. Alenka, M. Mozetic, and A. Zalar, Applied Surface Science 200, 94 (2002).

5. H. Asteman, J. E. Svensson, and L. G. Johansson, Oxidation of Metals 57, 193 (2002).

6. F. Riffard, H. Buscail, E. Caudron, R. Cueff, C. Issartel, S. ElMesski, and S. Perrier Materials, Science Forum 461-464, 175 (2004).

7. D. Monceau and B. Pieraggi, Oxidation of Metals 50, 477 (1998).

8. P. Kofstad, High-Temperature Corrosion (Elsevier, London, 1988).

9. M. Pijolat and M. Soustelle, Thermochimica Acta 478, 34 (2008).

10. K. Surla, F. Valdivieso, M. Pijolat, M. Soustelle, and M. Prin, Solid State Ionics 143, 355 (2001). 11. D. Young, High Temperature Oxidation and Corrosion of Metals (Elsevier, Amsterdam, 2008). 